\title{
Correction to: Regional variability in the response of alpine treelines to climate change
}

\section{Emma L. Davis ${ }^{1} \cdot$ Robert Brown $^{1} \cdot$ Lori Daniels $^{2} \cdot$ Trudy Kavanagh $^{3} \cdot$ Ze'ev Gedalof $^{1}$}

Published online: 18 August 2020

(C) Springer Nature B.V. 2020

\section{Correction to: Climatic Change https://doi.org/10.1007/s10584-020-02743-0}

The environmental lapse rate used to estimate historical treeline advance was incorrectly reported as $0.006{ }^{\circ} \mathrm{C} / 1000 \mathrm{~m}$; a value of $0.006^{\circ} \mathrm{C} / \mathrm{m}$ was used in the calculations.

Publisher's note Springer Nature remains neutral with regard to jurisdictional claims in published maps and institutional affiliations.

The online version of the original article can be found at https://doi.org/10.1007/s10584-020-02743-0

\section{Emma L. Davis}

emmalaureldavis@gmail.com

1 Department of Geography, Environment and Geomatics, University of Guelph, 50 Stone Road East, Guelph, ON N1G 2W1, Canada

2 Department of Forest and Conservation Sciences, University of British Columbia, 2424 Main Mall, Vancouver, BC V6T 1Z4, Canada

3 Department of Earth, Environmental and Geographic Sciences, University of British Columbia, 1177 Research Road, Kelowna, BC V1V 1V7, Canada 